\title{
Virtue Ethics and Moral Psychology. Editorial Note
}

\section{A. Campodonico ${ }^{1} \cdot$ C. Navarini $^{2}$}

Published online: 2 June 2020

(C) Springer Nature B.V. 2020

After more than sixty years from the pioneer work of Elizabeth Anscombe Modern Moral Philosophy (1958), Virtue Ethics (VE) has firmly established itself as a prominent paradigm within moral philosophy. Since its beginning, a wide range of scholars have been confronting several issues, ranging from the importance of character to the significance of happiness and flourishing; from the insufficiency of ethical rules to the critique of situationism; from the role of moral emotions to the difference between virtuous and automatic behavior. In addition, it has been inquiring more subtle topics such as the identity of the virtues - whether they are identifiable as personality traits or as skills -, the unity of virtues, as well as virtue taxonomy (Snow 2018). Particularly, in the last few years it has been intersecting with social sciences, specifically psychology, thus approaching studies and instruments of common interest, while also facing some skepticism especially on the philosophical side. In our view, the fruitful sharing of the philosophical and the psychological methodologies appears crucial for advancing a plausible, empirically informed virtue-ethical program.

Such an awareness arose gradually, facing various context-related problems. The first generation of virtue ethicists - with Anscombe, also Peter Geach, Philippa Foot, and Iris Murdoch had, on the one hand, to deal with analytical and emotivistic metaethics, and, on the other hand, with the two mainstream accounts of normative ethics: deontologism and utilitarianism or consequentialism. Such pivotal group of philosophers at the Oxford University - mostly related to Wittgenstein - argued that the core issue of moral philosophy had not been identified by existing models, either because they reduced the complexity of morality to its formal and logical aspects, or they exceeded in stressing the results of moral decisions and acts. By putting the agent, instead of their acts, at the center, they meant to concentrate their philosophical efforts on how to become good, integrating emotional and rational human dimensions, and also addressing what Anscombe termed philosophy of psychology (Anscombe 1958). The following generation of VE's followers

\section{Navarini}

claudia.navarini@unier.it
A. Campodonico
angelo.campodonico@unige.it

DAFIST (Department of Antiquities, Philosophy, and History), Università degli Studi di Genova, Via Balbi 30, 16126 Genova, Italy

2 School of Psychological Sciences and Techniques, Human Sciences Department, Università degli Studi Europea di Roma, Via degli Aldobrandeschi 190, 00163 Roma, Italy 
was a more varied and scattered group, among which we must mention Alasdair McIntyre, Charles Taylor, John McDowell, Martha Nussbaum, Julia Annas, Rosalind Hursthouse, Julia Driver, Julia Annas, Daniel Russell, and others, divided in different currents.

Simultaneously with their philosophical work, psychology started to take a keen interest in virtues. The two psychological issues that intertwined more with VE have been probably the situationist debate and the work on character strengths. While the first has progressively lost most of its vigor - after approximately twenty years of discussions on some challenging experiments coming from social psychology - the second has been gaining increasing relevance since 2004, when Peterson and Seligman published their Values in Action model, thus founding the so called Positive psychology. They presented a new perspective, claiming that psychological research should be devoted to studying, assessing, and promoting everybody's positive potentials, instead of focusing only on dysfunctional reactions. For this reason, they outlined the well-known schema of six virtues and 24 character strengths, which subsequently allowed them to operationalize and measure specific virtues and subvirtues (Peterson \& Seligman 2004). As previously mentioned, the spread of character studies drew some criticism, mostly deriving - contrary to situationism - from philosophy, which charged positive psychology with oversimplification. More recently, a new and promising field of interaction between VE and psychology has been developing thanks to cognitive psychology, which in turn matches with neuroscience and developmental psychology (Han 2016). Finally, a strong impulse to this interaction comes from moral psychology, specifically from research on moral decision, motivation, emotions, and purpose (Sinnott-Armstrong \& Miller 2017).

This special issue consists of eight articles by leading scholars working on the link between virtue theory and current psychological research, from a methodological, conceptual and applied perspective, also with a focus on educational implications. Notably, the idea of connecting these two epistemological worlds was stimulated by the discussions on the sidelines of the III International Conference of Aretai - Center of Virtues, which took place in Rome (Italy), in October 2018, and was followed by an intense exchange of intellectual feedbacks and scientific follow-ups. All contributors offer original solutions to groundbreaking issues at the crossroads between virtue ethics and empirical sciences, such as virtue measurement, the neurobiology of virtues, the virtue-as-skill paradigm and other empirically informed paradigms of virtue and virtue development.

More specifically, the essay by Nancy Snow, Jennifer Cole Wright, and Michael T. Warren focuses on a proposal of virtue measurement, integrating the Whole Trait Theory (WTT) with a neo-Aristotelian perspective. According to the authors, WTT might support empirically virtue theory, helping to identify the distinctions between cultural moral schemas and virtues, and between virtue-specific and virtue-general motivational states. As a result, WTT framework manifests itself as "broadly consistent with the motivational structure of virtues" and suitable to catching the specificity of practical wisdoms among the virtues.

The role of practical wisdom in the architecture of virtues is thematized by Mario De Caro and Maria Silvia Vaccarezza, who offer a revised version of the traditional Davidson's Principle of Charity, which they call Principle of Phronetic Charity (PPC). Through PPC and its consequences for VE, they present a new formulation of the unity-of-virtues issue, by suggesting a third position between holistic unitarianism, under the guidance of practical wisdom, and virtues fragmentation and isolation due to disunitarianism. Ultimately, they endorse "a form of molecularism, according to which virtues come neither individually nor as a whole, but rather as clusters". 
Skipping to the neuroethical aspects of virtues, Claudia Navarini's essay addresses the automaticity challenge to virtues, linking their neurobiological bases with the likelihood of virtuous behavior. The author contests that neuroscientific findings undermine the role of willpower and free will, while associating the likelihood of one's future moral actions preeminently to virtues, which would generate predictable behavioral patterns called Hypotheses of Action (HAs). Such HAs would preserve self-determination through the employment of Consent and Veto Power (CVP), which the author reaffirms.

Following this lead, Natasza Szutta underlines the notion of willpower, and specifically the virtues connected to it. Although they are necessary for the effectiveness of human actions, they are not always considered real virtues, since they could be directed to good as well as to evil goals. For this reason, the author recommends the association of such executive virtues with so called substantial virtues. At the same time, she characterizes the virtues of willpower as practical skills, which are compared to the empirical results of psychological studies, allowing advanced considerations about self-control, self-regulation, as well as will depletion.

Consistently with the previous contribution, Matt Stichter's essay takes the move from the virtue-as-skill model - which he depicted in previous works - focusing on an important possible consequence of it, namely moral failure. As Stichter points out, learning from moral failure is much more challenging than learning from failures as such, because emotions like anger, avoidance, defensiveness, but especially shame are involved. Therefore, a deeper analysis of the implications of emotions for virtue acquisition is needed, since highlighting the skill of emotion differentiation would be - in turn - crucial for virtue acquisition.

In line with the last two essays, which are concerned with specific virtues, while including them in the larger picture, Christian Miller's contribution focuses on the virtue of honesty, analyzing its motivational profile and finally advancing a pluralistic theory of honest motivation. Provided that everyday experience seems to attest how many actions are only seemingly honest, the author wants to ground this impression scientifically, offering an inquiry of the psychological and behavioral-economical literature on the topic of cheating. As a result, it would be apparent that "most people may fall short of the standards of honesty", therefore this virtue deserves more educational and intellectual deepening.

The last two articles reconnect with general aspects of virtue theory, specifically addressing moral epistemology and moral development in their connections to VE.

In his contribution, Michel Croce analyses the role of moral understanding in intellectual and practical agency, as well as the relationship between the ability of moral understanding and moral virtue. These two issues are receiving increasing attention both in moral epistemology and virtue ethics. The article advances both debates, questioning - on the one hand - the role of moral testimony in moral understanding. On the other hand, it challenges exemplarist ethicists to take a stand on "whether being a virtuous exemplar requires that one has the ability to engage in moral reasoning", suggesting an innovative interpretation of Zagzebski's theory toward a non-intellectualist direction.

The last (but not least) contribution of this volume is Darcia Narvaez's essay on moral and virtue development from the viewpoint of ecocentrism. This paper draws a transdisciplinary explanation of the destructive and unvirtuous results of industrialized societies, which would cause the degradation of nest components. According to neurosciences, such nest components "support normal development at all levels (e.g., neurobiological, social, psychological), laying the foundations for virtue". Therefore, the author claims, a deeper connection to the rest of nature appears essential to "restore relational atunement (engagement ethic), communal imagination, and respectful partnership with the natural world". 
In conclusion, we believe this issue fulfills its task of letting VE be provoked by psychological research, therefore having to weight its theoretical frames and ask itself whether a science of virtue is possible and desirable. From this dialogue, along with new questions, innovative and stronger accounts regarding virtues have arisen. We expect they will continue to bring further knowledge, insight, and practice in this promising moral field.

\section{References}

Anscombe, GEM (1958) Modern moral philosophy. Philosophy, 33(124):1-19

Han H, (2016) How can neuroscience contribute to moral philosophy, psychology and education based on aristotelian virtue ethics?. Int J Ethics Educ 1, 201-217. https://doi.org/10.1007/s40889-016-0016-9

Peterson C, \& Seligman ME (2004) Character strengths and virtues: A handbook and classification (Vol. 1). Oxford University Press

Sinnott-Armstrong W, \& Miller C (eds) (2017) Moral psychology, volume V: Virtue and Character. MIT Press Snow, NE (Ed) (2017) The Oxford handbook of virtue. Oxford University Press 